\title{
Post Procedural Hemorrhage
}

National Cancer Institute

\section{Source}

National Cancer Institute. Post Procedural Hemorrhage. NCI Thesaurus. Code C35656.

Bleeding occurring after a medical intervention. 